\title{
Selected Personality Traits and Intent to Leave: A Field Study in Insurance Corporations
}

\author{
Mahfuz Judeh \\ Business Administration Department, Applied Science Private University \\ PO Box 166, Amman 11931, Jordan \\ Tel: 962-79-665-8877Ｅ-mail: maj4040@hotmail.com
}

$\begin{array}{ll}\text { Received: February 19, } 2012 & \text { Accepted: March 8, } 2012 \quad \text { Published: May 1, } 2012 \\ \text { doi:10.5539/ibr.v5n5p88 } & \text { URL: http://dx.doi.org/10.5539/ibr.v5n5p88 }\end{array}$

The author is grateful to the Applied Science Private University, Amman, Jordan, for the part financial support granted to this research project.

\begin{abstract}
This study attempted to examine the effect of two selected personality traits on intent to leave. A theoretical framework was proposed to suggest link among the two variables and a questionnaire was distributed to collect data from employees in insurance corporations in Jordan. Of the 500 questionnaires distributed, 331 valid responses were received, resulting in a $66.2 \%$ response rate. The results revealed that both conscientiousness and extraversion were negatively related to intent to leave. As for the results of the demographic factors, the study showed that there were significant differences in intent to leave based on gender and age, while there were no significant differences due to marital status. Finally, this study suggested that management should adopt appropriate strategies and enhance human resource practices that lead to positive personality traits which lead to increased retention of employees.
\end{abstract}

Keywords: Personality traits, Conscientiousness, Extraversion, Intent to leave

\section{Introduction}

The retention of effecient employees in insurance companies has always been a challenge since employee turnover is a critical issue for them. However, the issue arises that there are many difficulties for many human resources departments in retaining employees. Insurance industry is important for the national economic development in Jordan, and it is necessary to study the problems it faces, especially when this industry experiences a considerable turnover rate. In general, high turnover rates increase human resource replacement costs, and affect the sustainability of organizational development. Therefore, studying the employee turnover phenomena of enterprise could help organizations predict and control employees turnover behaviors, and reduce their consequencies.

Personality traits concern human attributes which encompass biological, social, and cognitive factors that make a person different from others. Personality traits influence both individual and organizational behavior. Barrick and Mount (2005) accepted that behavior at work is influenced by personality. Furthermore, self-esteem, self-efficacy, job performance, and job satisfaction are all areas that have been linked to personality (Judge \& Bono, 2001). Generally speaking, personality traits are believed to be stable over time and unaffected by environmental factors (Hofstede \& McCrae, 2004; Mooradian \& Swan, 2006).

Two selected personality traits i.e. conscientiousness and extraversion, will be tested in the current research to show how they may contribute to one's intentions to leave the company. Specifically, this study was designed to address the following related questions:

(1) What is the influence of conscientiousness and on turnover intentions?

(2) What is the influence of extraversion on turnover intentions?

(3) Does the intent to leave or stay differ among employees due to demographic factors, such as gender, marital status, and age?

These kinds of relationships deserve further exploring, and as such, the current study adds to the management and organizational behavior literature through investigating the effect of personality traits on the intent to leave or stay. 


\section{Literature Review}

\subsection{Personality Traits}

The personality traits of consumers are another factor that is expected to influence the intention to leave. Many models of personality, exploring specific traits have been developed and studied. The "Five-Factor Model" has been commonly used with studies of personality traits. Some personality traits are found to be significant in predicting employees' work Performance (Suliman et al., 2010). Hogan et al. (1994) concluded that personality affect leadership behavior. The five domains of personality include extraversion, agreeableness, conscientiousness, emotional stability or neuroticism, and intellect, which are also referred to as openness to experience, (Costa \& McCrae, 1992; Mount \& Barrick, 1998).

Extraversion: Extraversion is a trait characterized by interest in other people, and trusting them. It is seen as a positive quality since it concerns the general sociability and includes traits such as human contacts, attention, active participation, and assertiveness.

Agreeableness: Agreeableness measures how able individuals are to get along with others. Agreeable individuals are generally decent and cheerful and therefore tend to be more involved in their tasks. They are friendly, courteous, altruistic, helpful, and they attempt to compromise their personal interests with others.

Conscientiousness: Conscientiousness is associated with being dependable, organized, punctual, and strong-willed. People with conscientiousness personalities plan ahead and they direct their impulses toward achievement.

Emotional Instability: Emotional Instability or neuroticism is associated with tension, irritability, and depression. This labeling of neuroticism seems to reflect the large number of negative items in this factor as well as the essentially negative viewpoint of human personality problems from past researchers in clinical and developmental psychology (Digman, 1990). Those with high neuroticism scores are more likely to be insecure and self-defeating.

Intellect: Intellect or openness to experience is the final factor of the five personality traits. It refers to how individuals make decisions in their lives in accordance with new ideas and creative thinking. Individuals with high scores on openness factor possess high levels of openness may be described as distinct, creative, flexible, and broad-minded.

Due to the scope of the current study, the author will examine two factors of personality traits, conscientiousness and extraversion. Based on this discussion, the following hypothesis is proposed:

H1. Conscientiousness has a significant negative impact on intent to leave.

H2. Extraversion has a significant negative impact on intent to leave

\subsection{Intent to Leave}

Intent to leave refers to the voluntary intention of individuals to leave their current organization or job. The cost of one leaves organization is not fixed, depending on his or her skill level. In fact, the cost of an individual quitting organization and get a replacement for him may include direct costs as advertising, recruiting, and training, as well as indirect costs, such as, lost work hours, cost of overtime, and cost of errors made by the new replacement. At the same time, the evidence suggests that it is proving difficult for organizations to find suitably qualified and experienced replacements for employees who leave (Shields \& Ward, 2001).

Voluntary turnover of good performers results in departing individuals to other competing organizations, and causing business secrets to be transferred to them. This drain demands management to motivate employees and create contingency plans. Researchers have empirically focused on intent to leave organizations. However, a more thorough study should include the intent to leave the position, as well as the intent to leave organization. Individuals may have an opportunity to work with another organization or to change their job. Investigating more than one type of intent to leave or to stay would better predict work behaviors. McCarthy et al. (2007) states that intention to stay or leave employment is the final step in the decision-making process, therefore, it is reasonable to suggest that understanding 'intent to stay or leave' might facilitate managers in introducing of appropriate retention strategies

It is the individuals' own estimated probability that they are permanently leaving the organization at some point in the near future (Vandenberg \& Nelson, 1999). Kennedy and Berger (1994) highlighted the finding that, in the hospitality industry, the highest turnover occurred during the first 4 weeks of employment. This could be attributed to the gap between new hires' expectations and poor human practices. These findings are consistent with a study by Lam et al. (2003) which concluded that employee turnover behavior occurs in the initial stage of employment, because new employees experience the new environment. 
Top management is demanded to work on career path plans for each employee. In addition to that, in employee selection, person-organization fit as the match between candidate and organization attributes should be considered. Schneider (1987) argues that organizations are one situation that people are attracted to, and remain with if they are a good fit with the organization, or leave if they are not a good fit with the organization. Increase person-organization fit to increase job satisfaction and to decrease intent to turnover, with the converse of those relationships being true, as well (Kristof-Brown et al., 2005; Verquer et al., 2003).

\subsection{Demographic Characteristics}

Demographic characteristics such as gender, marital status, and age will be tested as factors determining intention to leave. Thus, the current study tends to consider the following hypotheses:

H3. There are significant differences in intent to leave due to gender.

H4. There are significant differences in intent to leave due to marital status.

H5. There are significant differences in intent to leave due to age.

\section{Materials and Methods}

To determine the sample size, an analysis was conducted using the Raosoft (2004) Sample Size Calculator. With a confidence level of $95 \%$ and a margin of error that can be tolerated amounted .05 , and given a total population of 2114 employees working with insurance corporations in Jordan, a sample size of 326 participants was needed. A total of 500 questionnaires were randomly distributed, and only 331 were returned, resulting in a $66.2 \%$ response rate.

All responses were recorded for each case number and handled in a database for subsequent analysis. Non-response bias was tested by assessing the differences between the early and late respondents with regard to the means of all the variables (Armstrong \& Overton, 1977). It was concluded that there were no significant differences between the early and late respondents, suggesting that response bias was not a problem.

In addition to the demographic characteristics, the questionnaire is composed of two parts, namely: personality traits, intent to leave. Questions were answered using a five-point scale from 5 (strongly agree) to 1 (strongly disagree). Details of the two parts are described below.

Personality Traits: The current study employed five items for measuring consciousness and five items for measuring extraversion. These items were adapted from NEO-FFI, Borkenau and Ostendorf (1993), and John and Srivistava, S. (1999).

Intent to Leave: Survey instrument item scales were adapted from various studies, such as Bluedorn (1982), and McAllister (1995). The intent to stay was represented by four items.

\section{Results}

\subsection{Demographic Characteristics}

Table 1 showed all detailed demographic characteristics related to respondents.

Insert Table 1 Here

Among the 331 respondents, 65.6 percent $(n=217)$ were male and 34.4 percent $(n=114)$ were female. The majority of respondents $(61.6$ percent, $\mathrm{n}=204)$ were married and 38.4 percent $(\mathrm{n}=127)$ were single. Around 37.5 percent $(\mathrm{n}=124)$ were between $20-29$ years old.

\subsection{Descriptive Statistics}

Means, standard deviations, and were computed and shown in Table 2.

Insert Table 2 Here

As noticed, all means were above the midpoint of 3.00, while all standard deviation values were less than 1.00 . The reliability of constructs was measured by Cronbach's alpha, whereby; all values which ranged between .734 and .875 were above the internal consistency threshold of 0.70 (Bagozzi \& Yi, 1988).

\subsection{Hypotheses Testing}

Regression analysis was applied as a statistical tool to explore the impact of conscientiousness on the dependent variable, intent to leave. Examination of the results shown on Table 3 revealed that conscientiousness exhibited a negative significant impact on intent to leave (Beta $=-.128, \mathrm{R}^{2}=.016, \mathrm{p}<.05$ ). The findings supported H1.

Insert Table 3 Here 
As shown also on Table 3, results indicated that extraversion had a negative significant impact on intent to leave $\left(\right.$ Beta $\left.=-.339, \mathrm{R}^{2}=.115, \mathrm{p}<.05\right)$, which supported H2.

An independent samples t-test was applied in order to investigate the effect of gender or marital status on intent to leave. Results in Table 4 indicated that there were significant differences in intent to leave based on gender $(\mathrm{t}=$ 2.818; $\mathrm{p}<.01$ ), supporting $\mathrm{H} 3$.

Insert Table 4 Here

Furthermore, results indicated that there were no significant differences in intent to leave based on marital status $(\mathrm{t}=$ 1.828; $p>.05$ ), which did not support H4. Analysis of Variance was used to investigate the differences in intent to leave score due to age. Results in Table 4 showed that there were significant differences in intent to leave scores due to age $(\mathrm{F}=2.524 ; \mathrm{p}<.05)$, and supported H5.

\section{Discussion}

The current study linked two selected personality traits to intent to stay. It was expected that there would be a significant impact of conscientiousness and extraversion on intent to stay. The findings, however, supported H1 and $\mathrm{H} 2$.

The results of $\mathrm{H} 3$ provided empirical evidence that there were significant differences in intent to leave based on gender. This finding suggests that male employees are more likely to stay with their organizations than female employees and less likely to seek other employment opportunities or change their jobs. This result was consistent with the study of Göransson et al. (2009) which concluded that there were small effects of the demographic variables, indicating that men had stronger intentions to leave the organization.

The results of $\mathrm{H} 4$ proved that there were no significant differences in intent to leave scores due to marital status. This finding was congruent with the study of Ryan et al. (2011) which stated that marital status had no impact on intent to leave.

As for H5, the results showed that there were significant differences in intent to leave scores due to the age of respondents. The test results were congruent with previous findings of Krackhardt and Porter (1986) which concluded that younger people are less certain about their job patterns and hence tend to move more.

Overall, the findings of this study offer many implications for enhancing employee retention behaviors. The recruitment processes should attract people who are likely to follow managerial initiatives and controls. More attention should be paid to identifying and analyzing the root causes of staff turnover, and managing them to keep the turnover rate to the minimum. In conclusion, supporting personality traits will ultimately lead to reduced turnover intentions.

\section{Limitations of the Study}

This study has two main potential limitations of its findings. First, the study relied on the self-reported questionnaire to collect data on all indicators. To overcome this limitation, future research needs to be based more on objective measures. Second, it is important to note that the findings reported here are specific to one industry, and generalization across all industries is not possible. To solve this limitation, researchers can examine the various predictors of intent to leave within the context of their own studies.

\section{Recommendations}

Despite the above-mentioned limitations, this study provides greater understanding of the influence of personality traits on intent to leave. Furthermore, the conceptual framework of this study can be a guide to future research in the relationship between these constructs. Future studies should consider the associations of other aspects of work environment such as job involvement, employee empowerment, job characteristics, and organizational justice. Further testing of the relationships in this study on other industries is also needed to provide further insights into the predictors of intent to leave.

\section{References}

Armstrong, J. S., \& Overton, T. S. (1977). Estimating nonresponse bias in mail surveys. Journal of Marketing Research, 14(3), 396-402. http://dx.doi.org/10.2307/3150783

Bagozzi, R., \& Yi, Y. (1988). On the evaluation of structural equation models. Journal of the Academy of Marketing Science, 16, 74-94. http://dx.doi.org/10.1007/BF02723327

Barrick, M. R., \& Mount, M. K. (2005). Yes, personality matters: Moving on to more important matters. Human Performance, 18(4), 359-372. http://dx.doi.org/10.1207/s15327043hup1804_3 
Bluedorn, A. C. (1982). The theories of turnover: Causes, effects and meaning. Research in the Sociology of Organizations, 7(1), 75-128.

Borkenau, P., \& Ostendorf, F. (1993). NEO-Fünf-Faktoren Inventar (NEO-FFI) nach Costa und McCrae. Handanweisung (NEO Five Factor Inventory Manual). Hogrefe, Göttingen.

Costa, P. T. Jr., \& McCrae, R. R. (1992). NEO Personality Inventory and NEO Five-Factor Inventory Professional Manual. Odessa, FL: Psychological Assessment Resources, Inc.

Digman, J. M. (1990). Personality structure: Emergence of the five-factor model. Annual Review of Psychology, 41, 417-40. http://dx.doi.org/10.1146/annurev.ps.41.020190.002221

Göransson, S., Näswall, K., \& Sverke, M. (2009). Work-related health attributions: their impact on work attitudes. International Journal of Workplace Health Management, 2(1), 6-21. http://dx.doi.org/10.1108/17538350910945974

Hofstede, G., \& McCrae, R. R. (2004). Personality and culture revisited: Linking traits and dimensions of culture. Cross-Cultural Research, 38, 52-88. http://dx.doi.org/10.1177/1069397103259443

Hogan, R. T., Curphy, G. J., \& Hogan, J. (1994). What we know about leadership: Effectiveness and personality. American Psychologist, 49(6), 493-504. http://dx.doi.org/10.1037/0003-066X.49.6.493

John, O. P., \& Srivistava, S. (1999). The big five trait taxonomy: history, measurement, and theoretical perspectives. In L. A. Pervin and O. P. John (Eds.), Handbook of Personality: Theory and Research (pp. 102-38). New York, NY: Guilford Press.

Judge, T. A., \& Bono, J. E. (2001). Relationship of core self-evaluations traits self-esteem, generalized self- efficacy, locus of control, and emotional stability, with job satisfaction and job performance: A meta-analysis. Journal of Applied Psychology, 86(1), 80-92. http://dx.doi.org/10.1037/0021-9010.86.1.80

Kennedy, D. J., \& Berger, F. (1994). Newcomer socialization: Oriented to facts or feelings?. Cornell Hotel and Restaurant Administration Quarterly, 35(6), 58-71. http://dx.doi.org/10.1177/001088049403500613

Krackhardt, D., \& Porter, L. W. (1986). Turnover embedded in communication network. Journal of Applied Psychology, February.

Kristof-Brown, A., Zimmerman, R., \& Johnson, E. (2005). Consequences of individuals' fit at work: A meta-analysis of person-job, person-organization, person-group, and person-supervisor fit. Personnel Psychology, 58, 281-342. http://dx.doi.org/10.1111/j.1744-6570.2005.00672.x

Lam, T., Pine, R., \& Baum, T. (2003). Subjective norms: Effects on job satisfaction. Annuals of Tourism Research, 30(1), 160-177. http://dx.doi.org/10.1016/S0160-7383(02)00047-6

McAllister, D. J. (1995). Affect-and cognition-based trust as foundations for interpersonal cooperation in organizations. Academy of Management Journal, 38, 24-59. http://dx.doi.org/10.2307/256727

McCarthy, G., Tyrrell, M. P., \& Lehane, E. (2007). Intention to leave or stay in nursing. Journal of Nursing Management, 15, 248-255. http://dx.doi.org/10.1111/j.1365-2834.2007.00648.x

Mooradian, T., \& Swan, S. (2006). Personality and culture: The case of national extraversion and word-of-mouth. Journal of Business Research, 59, 778-785. http://dx.doi.org/10.1016/j.jbusres.2006.01.015

Mount, M. K., \& Barick, M. R. (1998). Five reasons why the "big five" article has been frequently cited. Personnel Psychology, 51, 849-857. http://dx.doi.org/10.1111/j.1744-6570.1998.tb00743.x

RaoSoft, Inc. (2004). Sample size calculator. www.raosoft.com/samplesize.html.

Ryan, C., Ghazali, H., \& Mohsin, A. (2011). Determinants of intention to leave a non-managerial job in the fast-food industry of West Malaysia. International Journal of Contemporary Hospitality Management, 23(3), 344-360. http://dx.doi.org/10.1108/09596111111122523.

Schneider, B. (1987). The people make the place. Personnel Psychology, 40, 437-454. http://dx.doi.org/10.1111/j.1744-6570.1987.tb00609.x

Shields, M. A., \& Ward, M. (2001). Improving nurse retention in the national health service in England: the impact of job satisfaction on intentions to quit. Journal of Health Economics, 20(5), 677-701. http://dx.doi.org/10.1016/S0167-6296(01)00092-3

Suliman, A. M., AbdelRahman, A. A., \& Abdalla, A. (2010). Personality traits and work performance in a duty-free industry. International Journal of Commerce and Management, 20(1), 64-82. http://dx.doi.org/10.1108/10569211011025961 
Vandenberg, R. J., \& Nelson, J. B. (1999). Disaggregating the motives underlying turnover intentions: When do intentions predict turnover behavior?. Human Relations, 52(10), 1313-1336. http://dx.doi.org/10.1177/001872679905201005

Verquer, M. L., Beehr, T. A., \& Wagner, S. H. (2003). A meta-analysis of relations between person-organization fit and work attitudes. Journal of Vocational Behavior, 63, 473-89. http://dx.doi.org/10.1016/S0001-8791(02)00036-2

Table 1. Demographic characteristics

\begin{tabular}{llll}
\hline & Characteristics & Number & \% \\
\hline \multirow{2}{*}{ Gender } & Male & 217 & 65.6 \\
& Female & 114 & 34.4 \\
\hline \multirow{2}{*}{ Marital Status } & Single & 127 & 38.4 \\
& Married & 204 & 61.6 \\
\hline Age & $<20$ years & 12 & 3.6 \\
& $20-29$ & 124 & 37.5 \\
& $30-39$ & 96 & 29.0 \\
& $40-49$ & 59 & 17.8 \\
& 50 and Above & 40 & 12.1 \\
\hline Total & & 382 & 100.0 \\
\hline
\end{tabular}

Table 2. Mean, standard deviation and reliability

\begin{tabular}{llll}
\hline Variables & Mean & Std. Deviation & Cronbach's Alpha \\
\hline Conscientiousness & 3.541 & .568 & .823 \\
Extraversion & 3.612 & .363 & .875 \\
Intent to Leave & 3.842 & .428 & .734 \\
\hline
\end{tabular}

Table 3. Results of linear regression analysis

\begin{tabular}{llllll}
\hline Independent Variable & Dependent Variable & $\mathrm{F}$ test value & $\mathrm{R}^{2}$ & Beta & Sig \\
\hline Intent to Leave & Conscientiousness & 5.481 & .016 & -.128 & .020 \\
Intent to Leave & Extraversion & 42.652 & .115 & -.339 & .000 \\
\hline
\end{tabular}

Table 4. Independent sample t-test and ANOVA for demographic factors

\begin{tabular}{lllll}
\hline Factor & Test Applied & Value & df & Sig \\
\hline Gender & Independent sample t-test & $\mathrm{t}=2.818$ & 329 & .005 \\
Marital Status & Independent sample t-test & $\mathrm{t}=1.828$ & 329 & .068 \\
Age & ANOVA & $\mathrm{F}=2.524$ & 4,326 & .041 \\
\hline
\end{tabular}

